\title{
Efficacy of reovirus therapy combined with cyclophosphamide and gene-modified cell vaccines on tumors induced in mice by HPV16-transformed cells
}

\author{
EVA SOBOTKOVA $^{1}$, MARTINA DUSKOVA ${ }^{1}$, TOMAS ECKSCHLAGER ${ }^{2}$ and VLADIMIR VONKA ${ }^{1}$ \\ ${ }^{1}$ Department of Experimental Virology, Institute of Hematology and Blood Transfusion \\ 12820 Prague; ${ }^{2}$ Department of Pediatric Hematology and Oncology, 2nd Medical School, \\ Charles University and University Hospital Motol, 15006 Prague, Czech Republic
}

Received March 12, 2008; Accepted May 6, 2008

DOI: 10.3892/ijo_00000024

\begin{abstract}
Oncolytic virotherapy is a novel approach to cancer treatment. In the present study we tested the ability of reovirus type 3 , strain Dearing, to suppress the growth of tumors induced in mice by HPV16-transformed TC-1 cells. In vitro, these cells are highly susceptible to the virus. In repeated in vivo tests the intratumoral inoculation of the virus resulted in only a minor slow-down of tumor growth, never in a complete cure. The effect of the treatment was not enhanced by the simultaneous administration of nononcogenic, genetically modified TC-1 cells expressing either IL-2, IL-12 or GM-CSF, and, in fact, the oncolytic effect of the virus was even less expressed in some instances. When cyclophosphamide was used in combination with the viral treatment, a synergistic effect resulting in tumor suppression was observed. In most instances the tumor regression was transitory, however, and was followed by tumor progression. The outcome of these experiments was dependent on the timing of the two treatments.
\end{abstract}

\section{Introduction}

Several classes of new anticancer agents are at present being promoted as potential supplements to the current anticancer therapy dominated by surgery, radiation therapy and chemotherapy. These new treatment options include monoclonal antibodies, biological response modifiers, modulators of signal transduction, inhibitors of neoangiogenesis and anticancer vaccines. An additional group of agents under investigation

Correspondence to: Professor Vladimir Vonka, Institute of Hematology and Blood Transfusion, Department of Experimental Virology, U Nemocnice 1, 12820 Praha 2, Czech Republic E-mail: vladimir.vonka@uhkt.cz

Key words: reovirus, HPV16-transformed cells, oncolytic effect, gene-modified cells, cyclophosphamide are oncolytic viruses, which can infect, replicate in and finally lyse tumor cells, but spare normal cells. A variety of oncolytic viruses have been used in the recent past for both preclinical and clinical studies (1-4). The viruses used can be divided into two classes. The first comprises viruses which are selectively oncolytic because of their natural properties. The best known naturally occurring oncolytic viruses are the reoviruses and the Newcastle disease virus, both with minimal pathogenicity for humans. The latter class consists of mutant viruses that have been rendered tumor selective, i.e. conditionally replicating, usually by the deletion of certain genes. The most widely used representatives of the latter group are mutants of herpesviruses and adenoviruses. None of the agents tested thus far is an ideal oncolytic virus. Such an agent should be highly specific for tumor cells even when delivered systematically; it should replicate quickly in dividing as well as in quiescent tumor cells and should spread well through the tumor mass yet remain safe for the patients treated. It should be weakly immunogenic, because immune reactions of the organism against the virus could limit its cytolytic activities. Ideally, infection with the virus should stimulate an effective antitumor immunity that would lead to the destruction of metastases.

One of the oncolytic viruses that at present are a focus of interest is the reovirus (respiratory enteric orphan virus). Reoviruses are highly prevalent among human populations and have a well-sustained safety profile in humans. According to some studies, by the age of 5 to 6 years, $50 \%$ of children show serological evidence of reovirus infection (5) and by adulthood most people have been exposed $(6,7)$. Taxonomically, reoviruses are members of the Reoviridae family. They are non-enveloped RNA viruses of icosahedral symmetry, with size range 60 to $80 \mathrm{~nm}$. The genome of the Orthoreovirus genus is segmented and contains 10 sections of doublestranded RNA, the overall genome size being $23 \mathrm{~kb}$. A link to their cancer-killing ability was established after the virus was found to reproduce well in various cancer cell lines. Reovirus preferentially propagates in tumor cells with an activated ras pathway $(8,9)$. This alteration can be found in approximately $50 \%$ of human malignancies. The reovirus serotype 3 strain Dearing is widely used in experimental undertakings both in laboratory animals and in clinical 
studies (10). It was the aim of the present study to examine the ability of reovirus Dearing to suppress the growth of tumors induced in mice by human papillomavirus type 16 (HPV16)-transformed TC-1 cells. The reovirus was either used alone or, in another set of experiments, the supportive roles of cyclophosphamide and of homologous gene-modified HPV 16-transformed cells expressing immunostimulating factors were tested.

\section{Materials and methods}

Cell lines and media. TC-1 cells were obtained through the courtesy of W.T. Wu (Johns Hopkins University, Baltimore, $\mathrm{MD})$. The cells were derived via the transfection of mouse (C57BL/6) lung cells with the HPV16 E6/E7 and activated $\mathrm{H}$-ras genes. TC-1 cells possess fibroblastoid morphology and induce rapidly growing, non-metastasizing subcutaneous tumors. One $\mathrm{TID}_{50}$ amounts to approximately $5 \times 10^{4}$ cells. At their surface they express MHC class I molecules and B7.1 co-stimulatory molecules (11).

281(IL-2 ${ }^{+}$) cells expressing mouse interleukin-2 (IL-2 production $14.5 \mathrm{ng} / 10^{6}$ cells $/ 24 \mathrm{~h}$ ), 231 (IL-12+) cells expressing mouse interleukin-12 (IL-12 production $99.5 \mathrm{ng} / 10^{6}$ cells/24 h) and $213\left(\mathrm{GM}^{\left.-\mathrm{CSF}^{+}\right)}\right.$cells expressing mouse granulocytemonocyte colony-stimulating factor (GM-CSF production $3.1 \mathrm{ng} / 10^{6}$ cells $/ 24 \mathrm{~h}$ ) were derived from a thymidine kinaseless ( (TK $^{-}$) subline of TC-1 cells previously isolated in our laboratory (unpublished data). Recombinant AAV viruses, which carry the HSV TK gene and the gene for the corresponding mouse cytokine (11), were used for the transduction. The gene-modified cells were selected in media supplemented with hypoxanthine, aminopterine and thymidine (HAT Media Supplement. Invitrogen, Carlsbad, CA). All three cell lines were non-oncogenic for syngeneic animals; however, one dose of $10^{6}$ of any of these cells was incapable of inducing protection against challenge with $10 \mathrm{TID}_{50}$ of the parental TC-1 cells (unpublished data). On the other hand, 231(IL-12+) cells, when used for treatment of mice bearing tumors induced by homologous parental cells, proved efficient in suppressing tumor growth (12). The Vero cells employed were provided by J. Cinátl Jr (W. Goethe University, Frankfurt/M, Germany). Both Vero and TC-1 cells were cultivated in D-MEM supplemented with $10 \%$ FCS. For cultivation of the gene-modified cells the media were supplemented with HAT.

Reovirus. Reovirus type 3, strain Dearing, was kindly provided by J. Cinátl Jr. In our laboratory it was propagated in Vero cells. Virus stocks were kept frozen at $-70^{\circ} \mathrm{C}$. Virus titres were determined by the standard plaque assay using an agar overlay. Comparisons of the sensitivity of Vero and TC- 1 cells were performed by parallel titrations by plaque technique and in 96-well plates (TPP, Switzerland) seeded with either cell type. Reovirus growth curves in Vero and TC-1 cells were constructed after infecting their cultures at MOI of 5 PFU per cell. Samples were taken at time 0 (i.e. at the time of withdrawing the unabsorbed virus inoculum adding cultivation medium and placing the cultures at $37^{\circ} \mathrm{C}$ ) and at 6, 20, 26 and $48 \mathrm{~h}$ post infection. After freezing and thawing the suspensions were spun down and the supernatants were titrated in Vero cells grown in 96-well plates.
Chemicals. Cyclophosphamide (Cy) was purchased from Farmos (Finland). It was administered intraperitoneally (i.p.) using $200 \mathrm{mg} / \mathrm{kg}$ in $0.2 \mathrm{ml}$ PBS per dose.

Animals, tumor induction and tumor treatment. C57BL/6 $\left(\mathrm{H}-2^{\mathrm{b}}\right)$ female mice (Charles River, Germany), 6-8 weeks old, were used. All work with animals was in accordance with the Guidelines for Animal Experimentation used in the Czech Republic. Before being injected, cells were washed three times with PBS. The gene-modified cells (see above) were then administered i.p., $10^{6}$ cells per dose. The animals inoculated were examined at least twice a week and were followed for up to 150 days. Tumor size was measured with a caliper and was expressed in $\mathrm{mm}^{2}$. Treatment invariably started when animals displayed small tumors $\left(\leq 10 \mathrm{~mm}^{2}\right)$. Special care was taken to ensure a similar distribution of tumors of different sizes in all experimental groups. A virus suspension containing $2 \times 10^{7} \mathrm{PFU}$ (as determined in Vero cells) of virus in $0.2 \mathrm{ml}$ PBS was administered intratumorally and in the immediate tumor neighbourhood. The construction of tumor growth curves for each experimental group was terminated on the day when the tumor size of the first mouse exceeded $400 \mathrm{~mm}^{2}$ or when the first mouse died. Upon completion of each experiment the surviving animals were humanely sacrificed.

Statistical analysis. Tumor formation was analysed in $2 \mathrm{x} 2$ contingency tables by two-tailed Fisher's exact test. Analysis of tumor growth curves was perfored by two-way analysis of variance. Calculations were done using GraphPad Prism Version 3 (GraphPad Software, San Diego, CA). A difference between groups was considered significant at $\mathrm{p}<0.05$.

\section{Results}

Growth of reovirus in Vero and TC-1 cells. The results of parallel titrations of the reovirus in Vero and TC- 1 cells using plaque technique and 96-well plates are shown in Table I. It can be seen that in both tests the virus titres were slightly higher in Vero than in TC- 1 cells thus indicating a lower sensitivity of the latter cells to minute amounts of the virus. Growth curves are indicated in Fig. 1. The virus replicated in both cells nearly equally well, but the titres achieved remained slightly higher in Vero than in TC-1 cells.

Effect of intratumoral reovirus administration. The results of a representative experiment, in which one dose of reovirus was injected into established tumors induced by TC-1 cells, are shown in Fig. 2. It can be seen that the inoculation of the virus resulted in a moderate slow-down of tumor growth $(\mathrm{p}<0.05)$. Nevertheless, the tumors continued to grow in all animals and none of the 6 mice treated was cured of the tumor. Similar small but statistically significant suppression of tumor growth, was observed in four repeated experiments (a total of 25 mice). This indicated that a single inoculation of the reovirus into the tumor was incapable of preventing tumor progression.

Effect of combinations of reovirus with cell-based vaccines. In the next experiment the inoculation of reovirus was combined with treatment with either $281\left(\mathrm{IL}-2^{+}\right)$cells or 
Table I. Reovirus titres in Vero and TC-1 cells.

\begin{tabular}{lcc}
\hline Cells & PFU/ml & $\mathrm{TCD}_{50} / \mathrm{ml}$ \\
\hline Vero & $10^{9}$ & $10^{8.25}$ \\
TC-1 & $7.5 \times 10^{7}$ & $10^{7.9}$ \\
\hline
\end{tabular}

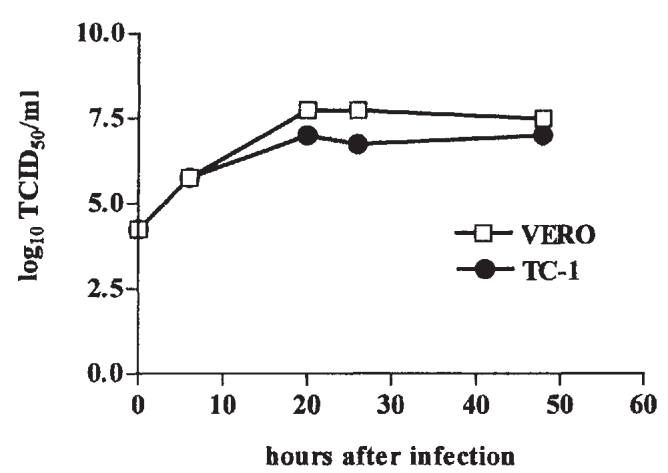

Figure 1. Growth of reovirus strain Dearing in Vero and TC-1 cells. The cultures were infected at MOI 5 PFU/cell.

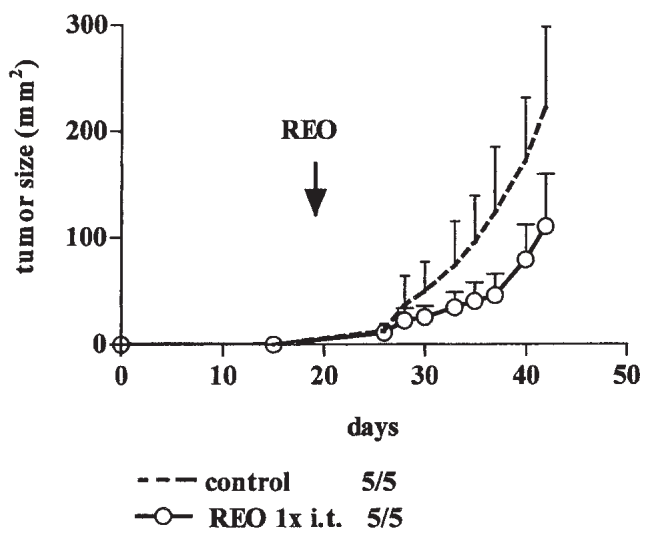

Figure 2. Results of treatment of tumors, induced in mice by TC-1 cells, by intratumoral inoculation of reovirus (REO). The figures indicate numbers of animals with growing tumors over animals treated.

231(IL-12+) cells (Fig. 3). The cells were administered on days 19 (i.e. simultaneously with the virus inoculum), 26, 33 and 40 after TC- 1 cell inoculation. Although every treatment, when applied alone, resulted in slowing down tumor growth $(p<0.01)$, the combination of reovirus with any of the cellbased vaccines did not produce a stronger effect. On the contrary, the combination of the virus with 281 (IL-2 ${ }^{+}$) cells decreased somewhat the efficacy of either of the separate treatments. Again, in all animals the tumors grew progressively. Similar results were obtained when $213\left(\mathrm{GM}^{\left.-\mathrm{CSF}^{+}\right)}\right.$ cells were substituted for $281\left(\mathrm{IL}-2^{+}\right)$or 231 (IL-12+) cells (Fig. 4). Co-treatment with these cells showed significant difference $(\mathrm{p}<0.01)$ but a lower slow-down effect than treatment with the reovirus alone. A combination of reovirus treatment with $213\left(\mathrm{GM}^{\left.-\mathrm{CSF}^{+}\right)}\right.$cells increased the effect of

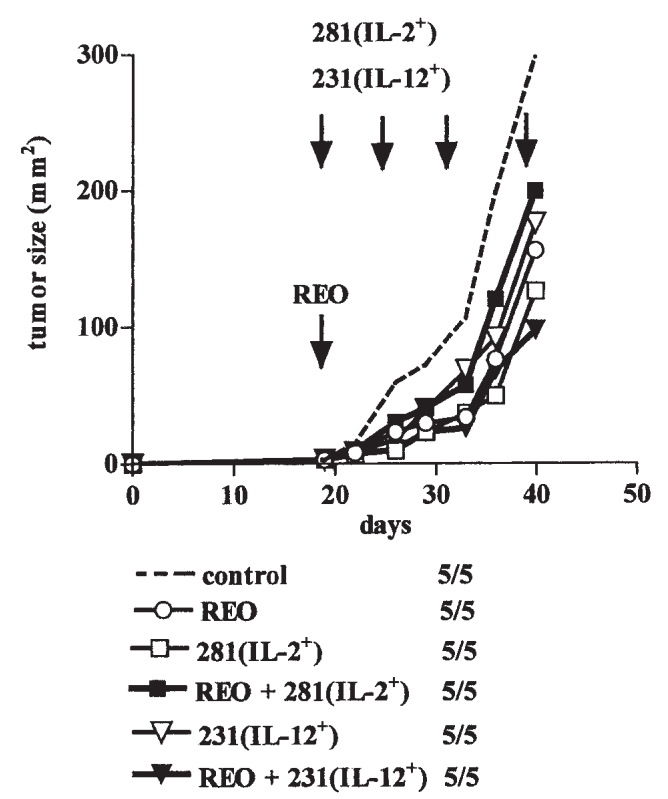

Figure 3. Results of treatment of tumors, induced in mice by TC-1 cells, by intratumoral inoculation of reovirus (REO), or by intraperitoneal inoculation of cell-based vaccines expressing either IL- 2 or IL-12, or by combinations of the reovirus and the vaccines.

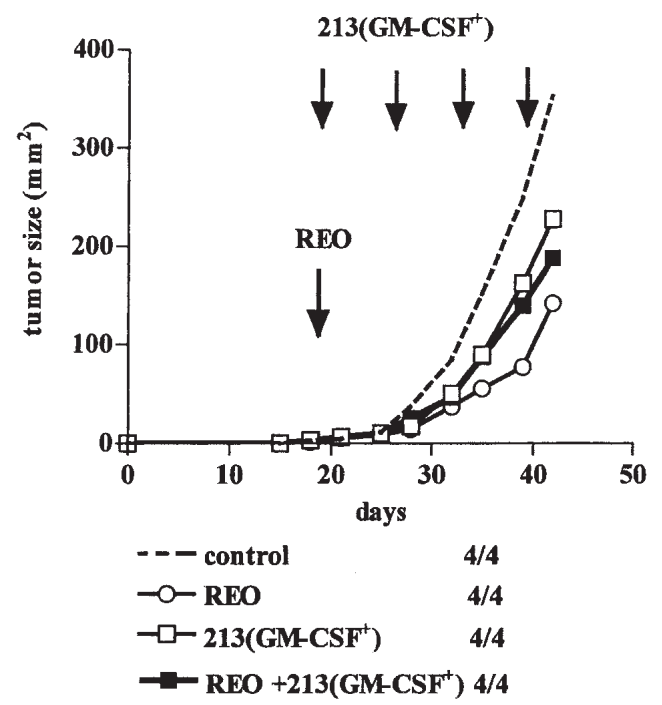

Figure 4. Results of treatment of tumors induced in mice by TC-1 cells by intratumoral inoculation of reovirus (REO), by intraperitoneal inoculation of a cell-based vaccine expressing GM-CSF, or by a combination of the reovirus and the vaccine.

the cell vaccine given alone; however, the difference was on the brink of significance $(\mathrm{p}=0.051)$. Moreover, the combination somewhat reduced the effect of the reovirus when used alone.

Effect of combination of reovirus and cyclophosphamide. As shown in Fig. 5A, Cy inoculated alone on day 18 resulted in marked suppression of TC-1-induced tumors which surpassed the effects of reovirus given alone (reovirus vs. Cy, $\mathrm{p}<0.001)$. Paradoxically, where Cy was administered either 

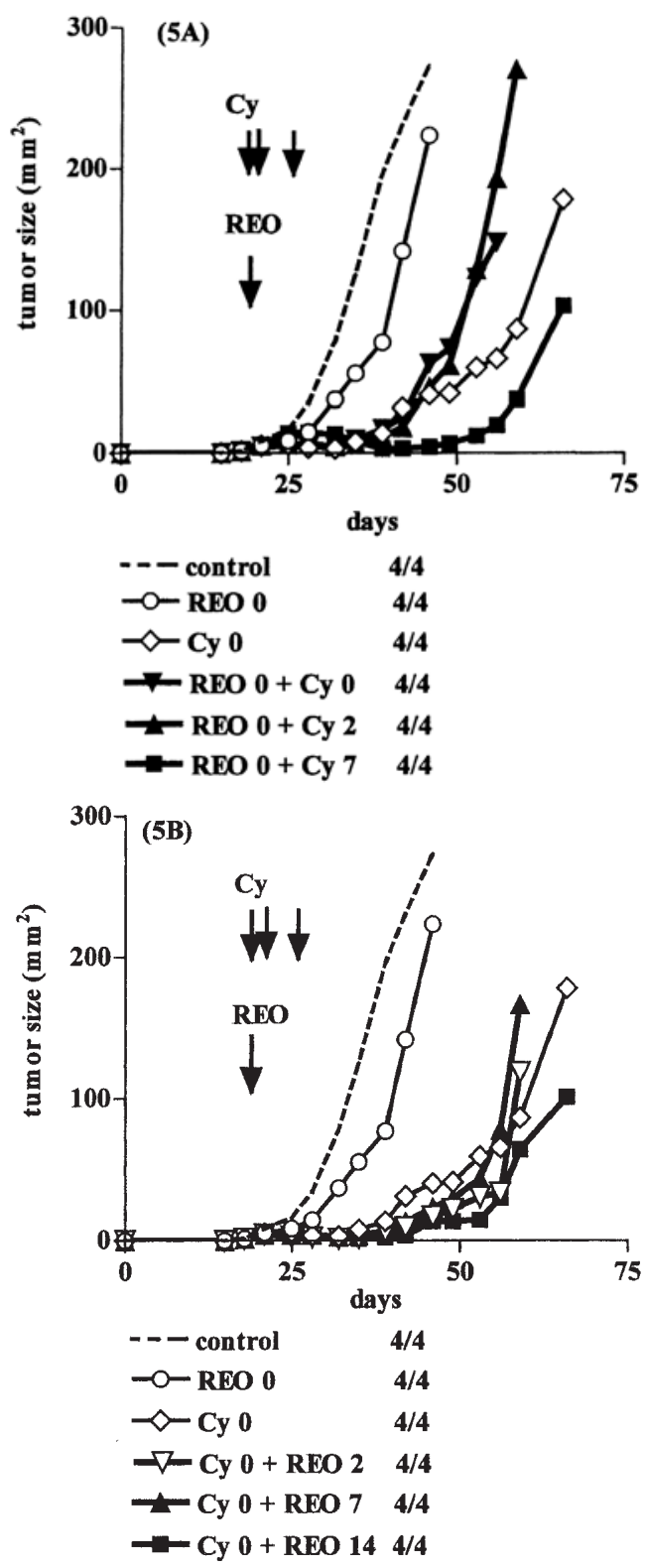

Figure 5. Results of treatment of tumors, induced in mice by TC-1 cells, by a single intratumoral dose of reovirus and a single intraperitoneal dose of cyclophosphamide (Cy). (A) Treatment with a single dose of reovirus (REO) alone, a single dose of $\mathrm{Cy}$ alone, or with their combinations; reovirus was inoculated first. (B) Treatment with a single dose of reovirus alone, a single dose of $\mathrm{Cy}$ alone, or with their combinations; Cy was inoculated first. Data shown in A and B are from one experiment.

simultaneously with or 2 days after reovirus, the beneficial effects were more pronounced than after reovirus given alone, but less marked than after Cy alone. However, when Cy was administered on day 25, i.e. 7 days after reovirus inoculation, a synergistic effect of the two treatments was apparent $(\mathrm{p}<0.005)$. This combined treatment reduced the primary growth of all tumors and postponed their secondary growth. A somewhat different phenomenon was observed when Cy was first injected on day 18 and this was followed by reovirus inoculation (Fig. $5 \mathrm{~B}$ ). When the virus was given on day 20 or 25 , i.e. 2 or 7 days after $\mathrm{Cy}$, the growth of the tumor was suppressed for a shorter time as compared with the effects of $\mathrm{Cy}$ alone. However, when the reovirus was injected into the tumors on day 32 , i.e. 14 days after $\mathrm{Cy}$

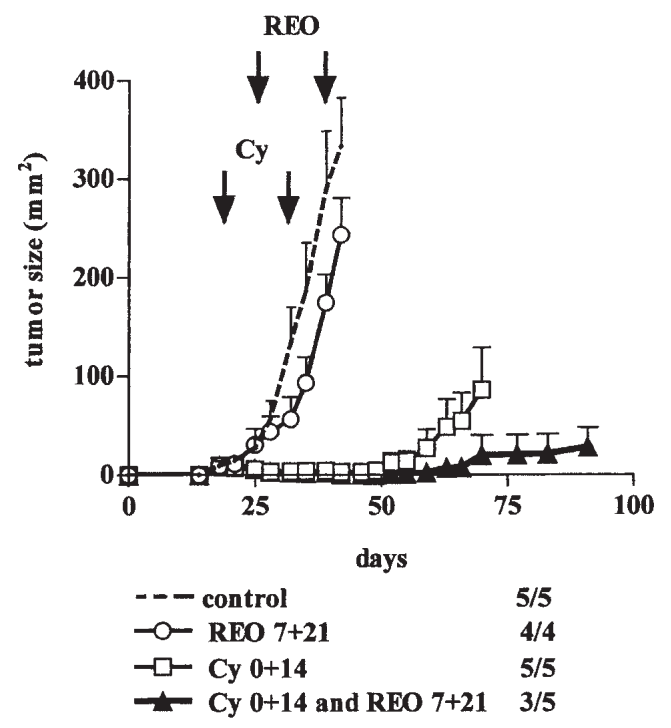

Figure 6. Results of treatment of tumors, induced in mice by TC-1 cells, by two intratumoral doses of reovirus (REO) plus two intraperitoneal doses of $\mathrm{Cy}$.

inoculation, there was significantly greater suppression of tumor growth as compared with Cy alone $(\mathrm{p}<0.05)$.

Based on the results shown in Fig. 5, in the subsequent experiment we tested the effects of repeated doses of both reovirus and $\mathrm{Cy}$. The results of this type of combination therapy are presented in Fig. 6. In this experiment, Cy was administered on days 18 and 32 and reovirus on days 25 and 39 after TC-1 cell inoculation. While reovirus inoculation produced only a weak effect on tumor growth, the effect of Cy was pronounced $(p<0.01)$. A combination of both treatments resulted in a further slow-down of tumor growth. The suppression was much stronger than after treatment with repeated doses of $\mathrm{Cy}$ alone $(\mathrm{p}<0.01)$. During the period between days 50 and 70 after TC- 1 cell inoculation, tumors became impalpable in four out of five animals, and, most significantly, they regressed permanently in two of them, thus indicating that these animals had been cured of their tumors.

\section{Discussion}

In the present study the effects of lytic treatment by reovirus, of tumors induced by mouse HPV16-transformed cells, were rather weak. Intratumoral inoculation of the virus resulted in a mere slow-down of tumor growth, which moreover was not very pronounced and in most experiments was just on the brink of significance. Tumors progressed in all mice treated with the virus alone. Our failure to achieve a more pronounced effect might partially have been due to the use of a low virus dose. Yang et al, for example, employed higher doses in another tumor system, and obtained encouraging results (13). In the present study, the effect achieved with the reovirus was comparable with the effects of vaccination with the gene-modified cell lines expressing IL-2, IL-12 or GM-CSF. There was no cumulative effect when their inoculation was combined with reovirus therapy. One possible explanation is that the immune reactivity enhanced by the cytokines produced by these cells accelerated the development of a strong immune response to the virus, thus preventing its spread within the tumour and leading to an early suppression 
of oncolysis. Although this might be the case, there is evidence from some other systems that once the reovirus has reached the tumor, the immune antiviral responses have not antagonized the viral infection (14). However, it is impossible to generalize from these, rather rare, observations. There are differences in the manner of virus spread (i.e. infection with released virus particles, spreading by cell-to-cell contact or formation of multinucleated syncytia), which can furthermore be influenced by the tumor microenvironment, i.e. the presence of physical intratumoral barriers and the extent of necrotic areas, by the ratio between the tumor and the stromal and other non-tumorous cells, the heterogeneity of the tumor cells and their changing character during tumor progression, which may include the selection of cells lacking virus receptors and thus rendered virus-resistant.

Synergistic effects were observed when intratumoral virus inoculation was combined with $\mathrm{Cy}$ treatment. This was in accord with plentiful other data already published which testify that the combination of virotherapy with chemotherapy may augment the efficacy of the former (15-19). In particular, the synergy was in agreement with results recently reported by Quiao et al (20), who used a combination of Cy and reovirus administered intravenously in another tumor system, in a manner similar to ours. It was evident in our present observations that the effects markedly depended on the timing of the two treatments. The best results were obtained when $\mathrm{Cy}$ inoculation was followed by reovirus treatment after several days (approximately one week). The reasons for this phenomenon are not fully understood at the moment. In vivo, $\mathrm{Cy}$ has both antiproliferative and immuno-modulatory effects $(21,22)$. While it can contribute to the development of antitumor immunity by suppressing regulatory T cells $(25,26)$, it also exhibits immunosuppressive activity. These effects are dose-dependent. Since we used a relatively high dose of $\mathrm{Cy}$, we assume that the $\mathrm{Cy}$ effects were due both to its cytostatic action and mitigation of the development of antiviral immunity. This reasoning seems to be in line with earlier observations that $\mathrm{Cy}$ can promote viral oncolysis by inhibiting several components of innate immunity which would otherwise limit the initial phase of the oncolytic virus infection (25-28); it is also in agreement with the recent demonstration that $\mathrm{Cy}$ suppresses the formation of reovirusneutralizing antibodies, which could strongly reduce intratumoral virus spread at the later stages of the treatment (20). It has also been shown by other investigators that immunosuppression by cyclosporine A, anti-CD4 and antiCD8 monoclonal antibodies (29) or by cyclosporin A alone (30) can augment the oncolytic activity of the virus. This has been evidenced by reductions of tumor size, prolongation of survival and inhibition of tumor regrowth.

To summarize, reovirus type 3 Dearing did not, in the present experimental setting, prove particularly effective in the treatment of tumors induced in mice by HPV16-transformed cells. The efficacy of the treatment was not enhanced by vaccination with gene-modified tumor cells producing various cytokines, but was clearly raised by $\mathrm{Cy}$, most likely owing to both its immunosuppressive and cytostatic action. The present data suggest that reovirus can be used in multimodel regimens of tumor treatment if its inoculation is properly timed.

\section{Acknowledgements}

The authors thank Mrs. Miluse Hanusova and Ms. Katerina Kernova for technical assistance. The research work was supported by grant no. 301/05/2240 from the Grant Agency of the Czech Republic.

\section{References}

1. Sinkovics JG and Horwath JC: Viral Therapy of Human Cancers. Marcel Dekker, New York, 2005.

2. Davis JJ and Fang B: Oncolytic virotherapy for cancer treatment: challenges and solutions. J Gene Med 7: 1380-1389, 2005.

3. Russell SJ and Peng KW: Viruses as anticancer drugs. Trends Pharmacol Sci 28: 326-333, 2007.

4. Vähä-Koskela MJ, Heikkilä JE and Hinkkanen AE: Oncolytic viruses in cancer therapy. Cancer Lett 254: 178-216, 2007.

5. Tai JH, Williams JV, Edwards KM, Wright PF, Crowe JE Jr and Dermody TS: Prevalence of reovirus-specific antibodies in young children in Nashville, Tennessee. J Infect Dis 191: 1221-1224, 2005.

6. Lerner AM, Cherry JD, Klein JO and Finland M: Infections with reoviruses. N Engl J Med 267: 947-952, 1962.

7. Minuk GY, Paul RW and Lee PW: The prevalence of antibodies to reovirus type 3 in adults with idiopathic cholestatic liver disease. J Med Virol 16: 55-60, 1985.

8. Strong JE, Coffey MC, Tang D, Sabinin P and Lee PW: The molecular basis of viral oncolysis: usurpation of the Ras signaling pathway by reovirus. EMBO J 17: 3351-3362, 1998.

9. Coffey MC, Strong JE, Forsyth PA and Lee PWK: Reovirus therapy of tumors with activated Ras pathway. Science 282: 1332-1334, 1998.

10. Figova K, Hrabeta $J$ and Eckschlager T: Reovirus-possible therapy of cancer. Neoplasma 53: 457-462, 2006.

11. Janouskova O, Sima P and Kunke D: Combined suicide gene and immunostimulatory gene therapy using AAV-mediated gene transfer to HPV-16 transformed mouse cells: decrease of oncogenicity and induction of protection. Int J Oncol 22: 569-577, 2003.

12. Indrova M, Bieblova J, Jandlova T, Vonka V, Pajtasz-Piasecka E and Reinis M: Chemotherapy, IL-2 gene therapy and combined adjuvant therapy of HPV 16-associated MHC class I-proficient and -deficient tumours. Int J Oncol 28: 253-259, 2006.

13. Yang WQ, Lun X, Palmer CA, et al: Efficacy and safety evaluation of human reovirus type 3 in immunocompetent animals: racine and nonhuman primates. Clin Cancer Res 10: 8561-8576, 2004.

14. Everts B and van der Poel HG: Replication-selective oncolytic viruses in the treatment of cancer. Cancer Gene Ther 12:141-161, 2005.

15. Heise C, Sampson-Johannes A, Williams A, McCormick F, Von Hoff DD and Kirn DH: ONYX-015, an E1B gene-attenuated adenovirus, causes tumor-specific cytolysis and antitumoral efficacy that can be augmented by standard chemotherapeutic agents. Nat Med 3: 639-645, 1997.

16. Heise C, Lemmon M and Kirn D: Efficacy with a replicationselective adenovirus plus cisplatin-based chemotherapy: dependence on sequencing but not $\mathrm{p} 53$ functional status or route of administration. Clin Cancer Res 6: 4908-4914, 2000.

17. Toyoizumi T, Mick R, Abbas AE, Kang EH, Kaiser LR and Molnar-Kimber KL: Combined therapy with chemotherapeutic agents and herpes simplex virus type 1 ICP34.5 mutant (HSV1716) in human non-small cell lung cancer. Hum Gene Ther 10: 3013-3029, 1999.

18. Cinatl J Jr, Cinatl J, Michaelis M, et al: Potent oncolytic activity of multimutated herpes simplex virus G207 in combination with vincristine against human rhabdomyosarcoma. Cancer Res 63: 1508-1514, 2003.

19. Li Y, Yu DC, Chen Y, Amin P, Zhang H, Nguyen N and Henderson DR: A hepatocellular carcinoma-specific adenovirus variant, CV890, eliminates distant human liver tumors in combination with doxorubicin. Cancer Res 61: 6428-6436, 2001.

20. Qiao J, Wang H, Kottke T, et al: Cyclophosphamide facilitates antitumor efficacy against subcutaneous tumors following intravenous delivery of reovirus. Clin Cancer Res 14: 259-269, 2008. 
21. Bass KK and Mastrangelo MJ: Immunopotentiation with lowdose cyclophosphamide in the active specific immunotherapy of cancer. Cancer Immunol Immunother 47: 1-12, 1998.

22. Lake RA and Robinson BW: Immunotherapy and chemotherapy - a practical partnership. Nat Rev Cancer 5: 397-405, 2005.

23. Ghiringhelli F, Larmonier N, Schmitt E, et al: $\mathrm{CD} 4{ }^{+} \mathrm{CD} 25^{+}$ regulatory $\mathrm{T}$ cells suppress tumor immunity but are sensitive to cyclophosphamide which allows immunotherapy of established tumors to be curative. Eur J Immunol 34: 336-344, 2004.

24. Motoyoshi Y, Kaminoda K, Saitoh O, et al: Different mechanisms for anti-tumor effects of low- and high-dose cyclophosphamide. Oncol Rep 16: 141-146, 2006.

25. Ikeda K, Wakimoto H, Ichikawa T, Jhung S, Hochberg FH, Louis DN and Chiocca EA: Complement depletion facilitates the infection of multiple brain tumors by an intravascular, replication-conditional herpes simplex virus mutant. J Virol 74: 4765-4775, 2000 .
26. Ikeda $\mathrm{K}$, Ichikawa $\mathrm{T}$, Wakimoto $\mathrm{H}$, et al: Oncolytic virus therapy of multiple tumors in the brain requires suppression of innate and elicited antiviral responses. Nat Med 5: 881-887, 1999.

27. Wakimoto $\mathrm{H}$, Ikeda $\mathrm{K}$, Abe $\mathrm{T}$, et al: The complement response against an oncolytic virus is species-specific in its activation pathways. Mol Ther 5: 275-282, 2002.

28. Kambara H, Saeki Y and Chiocca EA: Cyclophosphamide allows for in vivo dose reduction of a potent oncolytic virus. Cancer Res 65: 11255-11258, 2005.

29. Hirasawa K, Nishikawa SG, Norman KL, et al: Systemic reovirus therapy of metastatic cancer in immune-competent mice. Cancer Res 63: 348-353, 2003.

30. Smakman N, van der Bilt JD, van den Wollenberg DJ, Hoeben RC, Borel Rinkes IH and Kranenburg O: Immunosuppression promotes reovirus therapy of colorectal liver metastases. Cancer Gene Ther 13: 815-818, 2006. 